\title{
Research on the Present Situation of Internet Finance in China

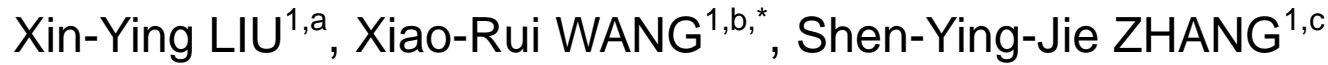 \\ ${ }^{1}$ Department of International Economics and Trade, Shandong University of Finance and Economics, Jinan, Shandong Province, 250014, China \\ aemail:sheila_guo1988@hotmail.com, bemail:wangxiaorui0303@163.com, email:zhangshenyingjie@163.com
}

Keywords: Internet finance, Virtual, Risk, Supervision, Measures.

\begin{abstract}
By enumerating four main modes of Internet financial development in China, this paper objectively analyzes the advantages of current Internet finance industry in China relative to traditional finance, and lists the liquidity, operational, credit, legal and operational risks in the process of development, And put forward corresponding suggestions and measures for these problems. This year will be a thriving year for China's Internet finance industry in 2017, a year of consolidation and control.
\end{abstract}

\section{Introduction}

Today's era is the Internet era, with the rapid development of Internet technology, we are inseparable from all aspects of Internet life. In the new economic situation, "Internet + Finance" quickly occupied a large number of market shares with its own advantages. Traditional financial institutions through the Internet's instant messaging technology, launched an efficient and efficient service model, but one of the premise is to fully ensure the safety of the entire business process. In short, Internet finance is not a simple combination of Internet technology and finance. It is a new area that needs to be innovated to meet the needs of the times and has a significant impact on new areas to be developed.

\section{China's Internet Finance Status Quo \\ China's Overall Status Quo}

In the new economic environment, the rapid development of internet finance benefits from its being different from the traditional financial services. It is not supervised by central banks and other regulatory authorities, and there are no restrictions on the establishment of the threshold. Again from the Internet level, Internet finance is convenient, efficient and accurate. Compared with traditional financial institutions, Internet finance is more rigid and flexible. With its unique characteristics of light application, fragmentation and timely financial management, To many small and medium enterprises of all ages. At present, our country is in a critical period of economic restructuring. Medium and small enterprises have accounted for $98 \%$ of the total number of Chinese enterprises. The impact of such a large group on the direction of China's economic development is undoubtedly enormous. Therefore, in the "Internet + Financial" pattern, the participants are not only traditional financial institutions such as commercial banks and investment companies.

\section{The Main Mode of Development}

\section{Crowdfunding}

The crowdfunding model is a model of "Internet finance," where creative people raise small amounts of money or other support for the public and then publicize the results of their own creative efforts to those funding backers. The crowdfunding platform provides a platform for such feedback, providing users with the idea of initiating fundraising, sorting out the information of the financier, finally showing the results openly and transparently, and finally splitting up with the fundraiser as a model of their profitability. Last year, the State Council, the Ministry of Industry and 
Information Technology, the Securities and Futures Commission, the Mutual Fund Association and other relevant departments have also issued various opinions and policies. Under the background of tighter financial regulation and standardized development, the crowdfunding platform for unhealthy development gradually withdraws from the market. Industry into the normative period. Here are some data of Crowdfunding industry in China in Table1.

Table 1 China’s Crowdfunding Industry Data 2013-2017

\begin{tabular}{|l|l|l|l|l|l|}
\hline Years & 2013 & 2014 & 2015 & 2016 & 2017 \\
\hline Normal operation crowdfunding platforms & 29 & 142 & 283 & 427 & 209 \\
\hline $\begin{array}{l}\text { National Crowdfunding Industry Total } \\
\text { Funding (100 million RMB) }\end{array}$ & 3.35 & 21.58 & 114.24 & 224.78 & 220.25 \\
\hline
\end{tabular}

\section{P2P Finance}

P2P finance, also known as P2P credit, means "Person-to-Person". The traditional small amount of loan costs is too high, it has spawned a lower cost, more convenient and quick loan P2P. P2P finance refers to the micro-credit transactions between individuals. In simple terms, it is to provide a virtual "market" with a third party and then act as an intermediary in such a market to help the lenders and creditors complete the transaction. In 2017, P2P finance mainly focused on the "compliance" direction, forming a comprehensive regulatory system of P2P online credit industry, pointing out the direction for the compliance development of the platform. With the promulgation of relevant policies, the phenomenon of "fast, partial and chaotic" in P2P financial industry has been fundamentally changed. Under the gradual improvement of the system, the turnover of the P2P financial industry has been rising year by year. Here are some data of P2P industry in China in Table2.

Table 2 China’s P2P Industry Data for 2013-2017

\begin{tabular}{|l|l|l|l|l|l|}
\hline Years & 2013 & 2014 & 2015 & 2016 & 2017 \\
\hline P2P platforms & 800 & 1575 & 2595 & 2448 & 1931 \\
\hline P2P market turnover (100 million RMB) & 893 & 3292 & 11805.65 & 28049.38 & 38952.35 \\
\hline
\end{tabular}

\section{Third-Party Payment}

Third-party payment refers to a non-financial institution that provides online payments, pre-payment issuance of prepaid cards, bank card receipts, and other payment activities as intermediaries prior to payers and payees. The clear advantage of this model is that this payment method has both the financial and the Internet's dual characteristics. The current market share of third-party or Alipay, TenPay followed, the formation of the first and second echelon. Other companies, including Lakala, Jingdong Payment and Baidu Wallet, jointly form the third tier with a small market share. Since 2013, the average transaction size of third-party payment markets has increased at an average annual rate of $50 \%$.Here are some data of Third party payment transaction in China in Table3.

Table 3 China’s third party payment transaction scale for 2013-2017

\begin{tabular}{|l|l|l|l|l|l|}
\hline Years & 2013 & 2014 & 2015 & 2016 & 2017 \\
\hline Third party payment transaction scale (billion RMB) & 17.2 & 23.3 & 31.2 & 58 & 102 \\
\hline
\end{tabular}

\section{Digital Currency (Virtual Currency)}

Digital currency, that is, virtual currency is a network virtual currency generated by the development of computer technology. Its main function is to purchase some virtual items. With the gradual expansion of the virtual currency audience, which makes the virtual currency in the real 
transaction acceptance is also slowly increased. Now more common are bitcoin, QQ coins, Amazon coins.

\section{Advantages of the Internet Financial Model}

\section{Reduce Transaction Costs}

The most prominent feature of Internet finance is to reduce the transaction costs. To balance treasure as an example, as a monetary fund, do not go to banks, fund companies and other agencies, but also not subject to a minimum limit of 1,000 yuan. Yu balance treasure the use of Internet technology, not only to make the purchase easier, more prominent is the cancellation of the purchase threshold of 1,000 yuan, the introduction of 0 threshold mechanism. As a result, Yu E Bao reduced the minimum purchase cost of the IMF from \$1,000 to \$1, which had to rely on Internet technology and a huge database.

\section{Achieve the Universal Meaning of Finance}

The traditional financial system is a place that excludes "small and retail investors," especially financial institutions such as banks. For ordinary people, they have only the role of savings. As for value-added services, services such as asset management are only open to VIP clients with vast assets. As a result, the investment threshold is set directly, and for the small majority of the average working-class people, even the qualifications of entry are not available. Until the advent of Internet finance, to the vast numbers of ordinary people who do not have much savings opportunities for financial management, the financial implications of the generalization of the show. In addition, with its own advantages, Internet finance has also solved the problem of lack of liquidity in traditional financial management, providing "financial fragmentation" and tailoring corresponding financial products to scattered funds, bringing scattered funds together and increasing customer profitability At the same time, also receive their own income. But also to a certain extent, stimulated some investors who did not engage in investment and wealth management business for investment interest and inspiration.

\section{Consolidate Credit Risk Management System}

Not so much Internet finance to enhance the current credit management of the financial industry, not to mention big data makes the credit risk management system has been a qualitative leap. Take credit card business, the role of big data statistics on the gradual improvement of personal credit system provides a huge impetus. Through Internet technology, card issuers can collect and evaluate the data on the income level, consumption records and asset status of the applicants and follow-up and follow-up on the final card issuers. Internet technology makes the credit risk management more specific, so that the financial industry can have a clear and clear evaluation standard, which is not possible in the traditional financial industry.

\section{Problems of Internet Finance}

Both the Internet and finance are inherently very risky, and Internet finance, as an innovative industry that combines the two, is less risky. The Internet financial model, the main show the following questions.

\section{Liquidity Risk}

Liquidity risk is a problem that can not be neglected in economic activities. After all, Internet finance is still a financial activity with some liquidity risk. Some current P2P companies, simply to protect the launch of their own business acceptance, blindly raise the rate of return, one at a time to attract new and old customers to invest money in themselves, to expand their market share, without considering the asset and liability maturity match or not , Tantamount to exacerbating the liquidity risk. 


\section{Credit Risk}

Internet finance has lowered the threshold for people's participation in financial activities, and on the other hand, it has brought a very big risk. The virtual nature of the Internet itself to a certain extent, increased credit risk. National credit mechanism is not yet complete, the possibility of default is very large. For the intermediary this link, there is still the risk of misappropriation of funds.

\section{Operational Risk}

In the course of business to use Internet technology to achieve the transaction, which should take into account these network accessories, equipment and technical level of the operator's technical level of the transaction impact. Under normal circumstances, this type of operational risk will not have much impact on the transaction. However, if there are operators' subjective self-serving interests and criminals using computer technology to illegally operate, this situation should be given special attention.

\section{Legal Risk}

As an emerging industry, internet finance has not yet had a mature legal system to monitor the development of Internet finance. This is also because emerging industries need to have a market test to improve. So in this process there are still many legal risks.

\section{Business Risk}

The leverage of Internet financial companies is very high, which gives a lot of criminals the opportunity to take advantage of. The resulting negative impact is that the products and services involved are complex in content and structure and involve a wide range of accountable personnel. As a result, business risks are ubiquitous and there are many unimaginable problems in any one link.

\section{Strategies for Coping with Problems in Internet Finance in China}

In the era of big data interconnection and interoperability, in order to prevent consumer information being stolen or misused, to ensure that consumers have the right to information on the risk of investment products, the central bank and the CBRC, CIRC and CSRC have strengthened their cooperation and endeavored to implement relevant monitoring activities. Prohibit illegal financing activities. Liu Shiyu, former vice president of the Central Bank, once listed three irresistible red lines of Internet finance: first, it can not confuse the red line of fund-raising; second, red lines that absorb public deposits; and third, red lines of fraud.

\section{For Liquidity Risk}

In response to this situation, the relevant regulatory authorities can establish a management index system, real-time monitoring of liquidity risk and assess the feedback to the relevant departments. We can also use big data to predict liquidity risk, if conditions and techniques permit, so we can largely avoid the liquidity risk.

\section{For Credit Risk}

We can access the industry threshold, the industry operating guidelines clearly defined and set some margin system. Related lending platform to timely and accurate information disclosure. In the meantime, the relevant state departments should improve the personal credit information system, speed up the overall exchange of information and expand the channels for collecting credit data.

\section{For Operational Risk}

On the one hand to improve the design of hardware and software to improve the use of simple and clear, and establish business practices and systems to reduce the possibility of misuse; Second, the need to strengthen training to improve operator familiarity with the operation of equipment; Third, 
to strengthen preparedness, For the relevant information to do security work.

\section{For Legal Risks}

Relevant departments should promptly promulgate relevant laws and regulations to stipulate all aspects of Internet finance and all responsible persons. We know that the law can not be formulated in a single step. We should give some time to adapt and formulate it. However, we must have some binding provisions in this process and constantly adjust and update the mechanism according to the actual situation. In addition, in the context of economic globalization, we must also attach importance to the relevant requirements of international law.

\section{For Business Risk}

Constantly learn new technologies, introduce professionals and develop safe and reliable technologies. For all aspects and individual responsible for the safety problems that can occur, you can set some security permissions to be protected. The relevant regulatory authorities should promptly introduce the appropriate regulatory measures and supervision of the treaty, to ensure external security issues.

\section{Summary}

Internet finance, in the final analysis, is still the financial industry. For the Internet finance industry in China in 2017, it is booming year, and it is also a year of regulating integration. In the next period of time, relevant state departments and organizations will still rectify the various chaos that regulate the Internet finance industry through the promulgation of relevant laws and regulations, and the industry regulation will be greatly enhanced. It is hoped that the Internet finance industry in China will set its standard in support of Internet technology and related supervision rules in order to achieve the ultimate goal of serving the real economy. This is the correct direction for the development of Internet finance in China.

\section{Acknowledgement}

This research was financially supported by the Study on the Optimization Effect of OFDI on China along the Belt and Roads; "Reform of China's Economy and Financial System" (English for International Students), Brand Course for English Teaching for Foreign Students in 2013 by the Ministry of Education; Shandong University of Finance and Economics International Exchange and Cooperation - Curriculum Internationalization Program International Business with Czech Republic Prague Economic University, 2017

\section{References}

[1]PingXIE., Internet Finance Status [N]. The Financial Times, 2010-10-12 [2].(In Chinese)

[2]Hu ZHANG, The main risks and problems of the current Internet finance [J]. Consensus .2015-12-29.(In Chinese)

[3]Jing CHEN, Comparative analysis of Internet finance and traditional finance [N]. Cooperative economy and technology(2015).(In Chinese)

[4] Xiao-Jin ZHONG, Six major Internet finance model for the development of the third party to pay the hottest [J / OL]. China Economic.2014-07-06 (9).(In Chinese)

[5]Hao-Cheng SUN / Li Li, Analysis of Internet Finance Development and Supervision [J]. Modern Economic Information .2014.18.02.(In Chinese)

[6] Information on http://www.wdzj.com,(In Chinese) 